\title{
IDENTIFYING FRAILTY SYNDROME WITH TUG TEST IN HOME-DWELLING ELDERLY
}

\author{
Identificação da síndrome da fragilidade com o teste TUG \\ em idosos residentes na comunidade
}

\author{
Lidiane Isabel Filippinª, Fernanda Miragliaa, José Carlos Carvalho Leitea, \\ Rafael Chakr ${ }^{\mathrm{b}}$, Nathalia Cardoso Oliveirac, Dalvana Dutra Berwanger ${ }^{\mathrm{b}}$
}

INTRODUCTION: Frailty is an important geriatric syndrome linked to increased mortality, morbidity and the risk of falls Detection of pre-frail and early frail individuals is essential to minimize adverse health outcomes, enabling effective interdisciplinary interventions. OBJECTIVE: To identify frailty syndrome with Timed Up and Go (TUG) test in home-dwelling elderly. METHODS: A home-based cross-sectional study was carried out with 322 elderly people living in a Southern city of Brazil. The Fried frailty criteria was used in order to assess the levels of frailty; the TUG score was investigated as a possible predictor of frailty. The diagnostic ability of different cut-off points for the TUG test was evaluated using the ROC curve. RESULTS: ROC curve analysis for the TUG test, a value of eight seconds was identified as the good cut-off point for the screening of the frailty syndrome. The AUROC was 0.775 , with a sensitivity of $85.0 \%$, specificity of $59.5 \%$ and negative predictive value of $78.6 \%$. CONCLUSIONS: Considering the limitations of a single test to accomplish the overall complexity of frailty syndrome, in the present study, TUG test was a good screening tool in home-dwelling elderly.

KEYWORDS: cross-sectional studies; frail elderly; primary health care; aging; psychometrics.

INTRODUÇÃO: A fragilidade é uma importante síndrome geriátrica associada ao aumento da mortalidade, morbidade e risco de quedas. A detecção de indivíduos pré-frágeis e frágeis precoces é essencial para minimizar os efeitos adversos à saúde, possibilitando intervenções interdisciplinares eficazes. OBJETIVO: Identificar a síndrome de fragilidade com o teste Timed Up and Go (TUG) em idosos domiciliares. MÉTODOS: Estudo transversal de base domiciliar, com 322 idosos residentes em uma cidade do Sul do Brasil. O critério de fragilidade de Fried foi utilizado para avaliar os níveis de fragilidade; O teste TUG foi investigado como um possível preditor de fragilidade. A capacidade diagnóstica de diferentes pontos de corte para o teste TUG foi avaliada utilizando a curva ROC. RESULTADOS: A análise da curva ROC para o teste TUG, identificou-se um valor de oito segundos como o bom ponto de corte para a triagem da síndrome de fragilidade. O AUROC foi de 0,775, com sensibilidade de 85,0\%, especificidade de 59,5\% e valor preditivo negativo de 78,6\%. CONCLUSÕES: Considerando as limitações de um único teste para realizar a complexidade geral da síndrome de fragilidade, no presente estudo, o teste TUG foi uma boa ferramenta de rastreamento em idosos domiciliares.

PALAVRAS-CHAVE: estudos transversais; idoso fragilizado; atenção primária à saúde; envelhecimento; psicometria.

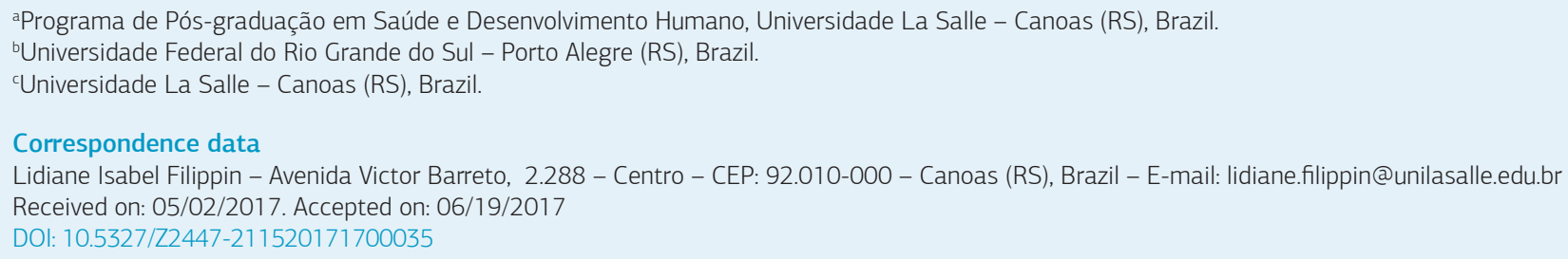




\section{INTRODUCTION}

Aging has attracted attention for its societal effects in many parts of the world. Population aging is associated with rising numbers and proportions of the elderly population within a society. In Brazil, this population is aging rapidly; according to the Brazilian Institute of Geography and Statistics (IBGE), the proportion of people older than 65 years will reach $22 \%$ in 2025 , becoming the sixth largest elderly population in the world. ${ }^{1}$ On the one hand, the aging process represents a human success story of increased longevity, with enhanced life expectancy. On the other hand, functional decline is strongly associated with age. The most common functional losses are disability, falls, and higher risks of comorbidities, hospitalization, and mortality. ${ }^{2-7}$

For this reason, early recognition and improvement of functional impairment seems to be vital for healthy aging. Elderly at risk of frailty are usually independent but present minor functional impairment. ${ }^{7}$

Frailty is an age-related syndrome characterized by decreased reserve and resistance to stressors, sharing risk factors and interacting with other conditions, such as falls, delirium and incontinence. Currently, frailty is consider a multidimensional clinical syndrome that overlaps with other aging conditions and causes negative impact on the lives of the elderly and their family members. Frailty has been associated with a number of risk factors, including older age and female sex, ${ }^{8}$ poverty and lower education, ${ }^{9,10}$ smoking, extreme body mass index ${ }^{11}$ and the presence of chronic illness. ${ }^{12}$ Frail persons are at greater risk for functional loss, hospitalizations or hospital readmissions and in-hospital mortality. ${ }^{13-16}$ Frailty is becoming one of the most significant clinical conditions affecting elderly people ("major geriatric syndrome"), with a prevalence of $10 \%$ for those older than 65 years and $30 \%$ for those older than 80 years. ${ }^{3,6,17}$ Although frailty is a frequent phenomenon in the elderly, its concept and the pathophysiological changes underlying and preceding frailty are not clearly known, consequently rendering the precise definition and prompt diagnosis a difficult task.

Although it has great impact on the health of the elderly, frailty has gotten little attention in the primary care, especially because its manifestations are often subtle. Therefore, researchers have suggested that early detection ("elderly at risk of frailty") is key in minimizing health risks and optimizing early and targeted treatment.

Currently, there are few low-cost, reproducible and easily applicable screening tools for early frailty recognition. ${ }^{18}$ Detection of pre-frail and early frail individuals is essential to minimize adverse health outcomes, enabling effective interdisciplinary interventions. The Timed Up and Go test (TUG) is a standardized mobility assessment. The time taken to complete the test has been commonly used to assess the risk of falls in elderly people and has recently been demonstrated as a strong predictor of frailty. ${ }^{19,20}$ The use of functional tests in frailty screening offers great advantages because it does not depend on the memory of patients and the subjectivity of screening questionnaires, as cognitive impairment and mood disorders could seriously bias evaluation. This study aimed, therefore, to evaluate the accuracy of the TUG test as a screening tool for frailty syndrome in elderly subjects seen in primary care.

\section{METHODS}

This is a cross-sectional, home-based study, with primary data collection on health features of urban elderlies living in a Southern Brazilian city. The participating subjects were sampled as follows:

- $20 \%$ out of the 51 census sectors were randomly selected;

- in order to ensure self-weighted sampling, a convenience sample of $40 \%$ of the target population was drawn out of the selected sectors;

- an evaluation (questionnaires and physical examination) was conducted by trained fieldworkers in standardized individual interviews at the participants' home.

The sample size calculation was based on the prevalence of frailty found in other Brazilian urban areas (9.1\%), ${ }^{21}$ with a significance level of $5 \%$, and absolute precision of $3 \%$. The calculated sample size was of 290 elderly individuals. The final sample included 322 elderlies, considering 10\% for statistical adjustments. Subjects with severe clinical weakness, bedridden patients, those with a history of arm or hand surgery in the three months prior to data collection or who underwent surgery of cataract or retina within the six weeks prior to the interview, wheelchair dependents, those with hypertension ( $>140 / 90 \mathrm{mmHg}$ ), with or without the control of antihypertensive drugs, as well as amputees, were excluded (Figure 1). Informed consent was obtained from all individuals participants include in the study.

\section{Instruments}

Sociodemographic information: It included gender, skin color (Caucasian or non-Caucasian), age (in years), education (in years), marital status (with companion or without companion), occupation and family income. The level of education (in years) was analyzed as a continuous variable. Marital 
status was divided into two categories: married (married or living with a partner in a stable relationship) or unmarried/ single (divorced, separated or widowed). Income was measured by the number of Brazilian monthly minimum salaries $(\mathrm{R} \$ 937.00=\mathrm{US} \$ 297.46)$, and the family income was classified in two categories: up to three (US\$ $\leq 892.38$ ) or more than three times the minimum salary $(>892.38)$.

\section{Covariates}

The functional performance was accessed by the following physical tests:

1. Timed Up and Go test (TUG). The TUG test quantifies functional mobility in seconds,

2. Handgrip Strength test? and

3. Lower Limbs Strength test

The person has to stand from a standardized chair, walk a straight three-meter path, turn around, walk towards the chair and sit down again. Before each test, the participants received explanations and practical demonstrations, in order to ensure a correct performance without any risk. The Handgrip strength test quantifies the handgrip strength in Kgf (kilogram-force) with the use of a digital hand dynamometer $\left(\mathrm{Camry}^{\circledR}\right)$ adjusted to each person according to the size of their hands. The test was conducted in the dominant member, with the subjects sitting, the upper limb supported on a hard surface, the elbow at $90^{\circ}$ flexion and the forearm extended forward. Participants were asked to press the device as hard as possible for five seconds. The procedure to measure handgrip strength was conducted three times, with one-minute intervals, and the average of time measurements was considered as the final value. The performance in this test was evaluated using the classification described by Alexandre et al.,22 (reference values: $20 \mathrm{kgf}$ for women and $30 \mathrm{kgf}$ for men). The Lower Limbs Strength test measures the strength of the lower limbs by the maximum number of sit-stand-sit cycles completed during 30 seconds according to the battery of physical tests by Fullerton, proposed by Rikli and Jones and Jones et al..$^{23,24}$

Frailty status

Fried and colleagues developed five criteria (weight loss, exhaustion, low physical activity, slowness and weakness) to

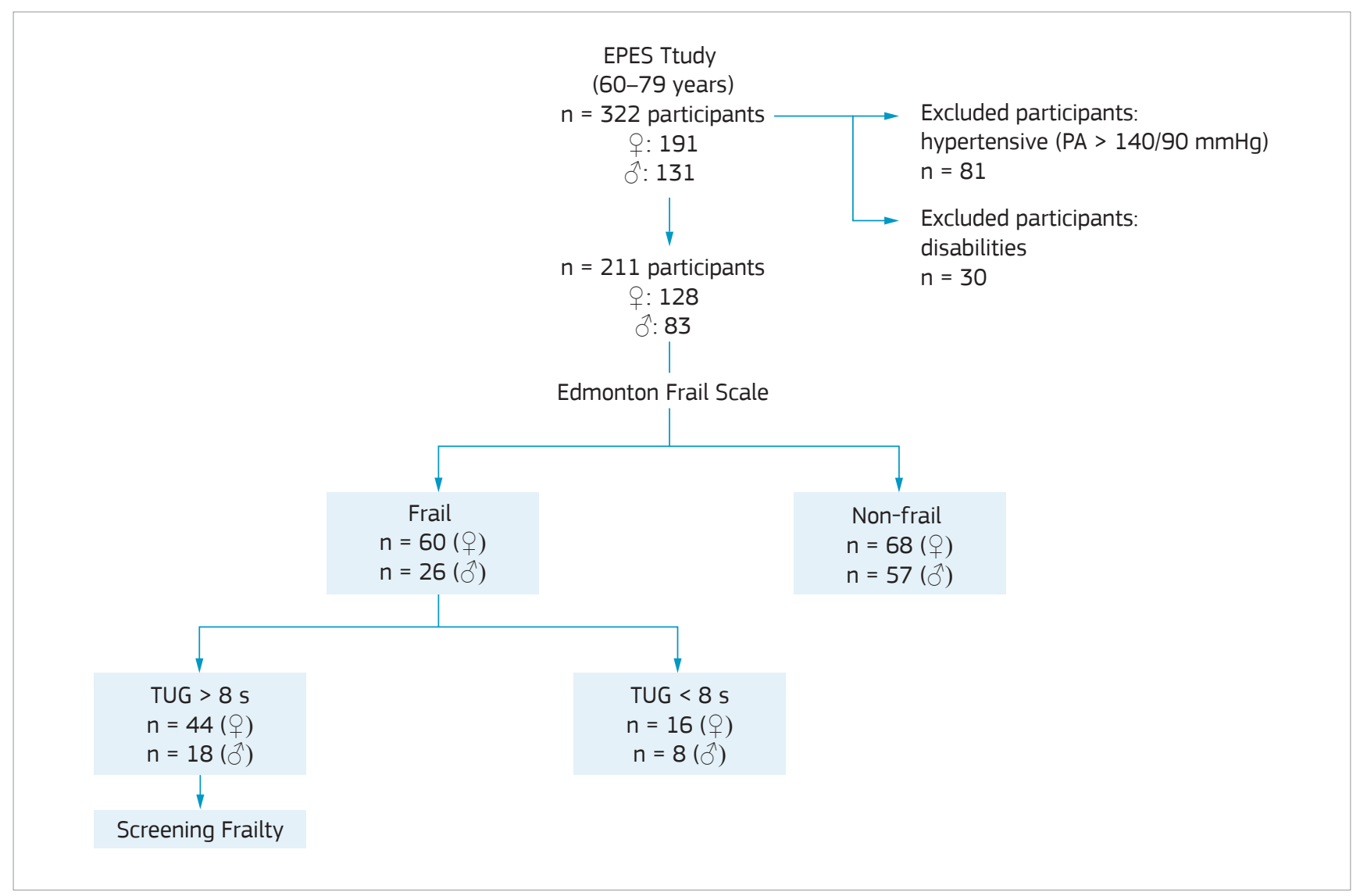

Figure 1 The prevalence of frailty using the Edmonton Frail Scale and Timed up and Go test. 
be used for identifying frail older people. ${ }^{6}$ In contrast with the original criteria, we replaced an Exhaustion measurement of the Center for Epidemiologic Studies Depression (CES-D) scale by one question: "Do you often feel tired or exhausted?". If the answer was "yes", the individuals should show on a scale, from zero to ten, the grade according to their sensation of exhaustion. On this scale, zero means "no sensation of exhaustion", and ten "high sensation of exhaustion". This criterion would be considered when participants answered: "sensation of exhaustion is higher than or equal to seven". ${ }^{25}$ Weight loss was measured using the question: "In the last year, have you lost more than $3 \mathrm{~kg}$ unintentionally? (i.e. not due to dieting or exercise)". This question is the same proposed by Fried and colleagues, only pounds were replaced by kilograms. This criterion was met when the participant answered "yes". ${ }^{26}$ Low physical activity was not measured using the Minnesota Leisure Time Activity Questionnaire, as proposed by Fried and colleagues. Instead, a slightly adjusted version of the International Physical Activity Questionnaire (IPAQ) was used. ${ }^{27,28}$ The full amount was calculated in carrying out activities for one week, stratified by gender and divided by quintiles. This was considered positive frailty the elderly in the smallest quintiles $(20.0 \%$ least active ones).

Slowness/walk time was measured using the gait speed test, based on the Short Physical Performance Battery Assessing Lower Extremity Function. ${ }^{29}$ Participants were instructed to "walk at your usual speed, just as if you were walking down the street to go to the store". The slowest $20 \%$ of individuals were considered to represent low physical performance. Weakness/gripstrength was assessed with handgrip strength in $\mathrm{kg}$ using a hand-held dynamometer (Sammons Preston Rolyan, 4, Sammons Court, Bolingbrook, IL, 60440). During the test, the participant was in a sitting position, with elbow and forearm resting on a table and palms facing up. The participant was prompted to grip the device using as much strength as possible. The grip size was adjustable so that each participant, regardless of size, could feel comfortable while squeezing the grip. The test was performed twice in the dominant limb, with a 1 -min rest between tests, and the higher value of the two trials was used for scoring. The cut-off points of $<30 \mathrm{~kg}$ for men and $<20 \mathrm{~kg}$ for women were considered to represent low muscle strength. ${ }^{22}$ The stages of frailty, based on the Fried criteria, were defined as follows: a score of 0 means that a person is robust or not frail. Persons with a score of 1 or 2 are at intermediate risk for adverse outcomes or are considered to be pre-frail. A score of 3-5 indicates that someone is frail. ${ }^{30}$

\section{Analyses}

For the statistical analysis, the absolute frequencies, means, and standard deviations of the descriptive measures of the population characteristics were calculated. The association between the indicators of physical performance (independent variable) and frailty (dependent variable) was tested using the technique of generalized linear models, by Poisson regression. Robust adjusted models were calculated in order to estimate the odds ratio (OR), with the respective confidence intervals of $95 \%$ ( $95 \% \mathrm{CI})$. The predictors of frailty were assessed using a sequence of two Poisson regression models. Initially, a bivariate model (unadjusted) was set up with each predictive variable and frailty (dependent variable). Next, a second model (adjusted) was constructed by taking the predictors into account. Variables selected for inclusion in the adjusted model were based on their significance level (e.g., $p<0.2)$ in bivariate analyses.

The diagnostic power for frailty according to physical performance and the identification of the best cut-off were evaluated using the parameters provided by the receiver operating characteristic (ROC) curves obtained from the sensitivity, specificity, positive and negative predictive values. In all analyzes, the significance level adopted was of 5\% $(\alpha=0.05)$. The data were analyzed in the Statistical Package for Social Sciences for Windows (SPSS 21.0, 2013, SPSS Inc, Chicago, IL).

\section{RESULTS}

Based on our sampling methods, 322 elderly subjects were interviewed. Table 1 shows a comparative analysis of the participants by frailty status. Among the participants, $60.6 \%$ $(\mathrm{n}=195)$ were women, $91.3 \%(\mathrm{n}=294)$ were Caucasian, $64.9 \%$ $(\mathrm{n}=209)$ were retirees, and $57.7 \%(\mathrm{n}=186)$ were married or living with a partner. Among the participants, $23.0 \%$ were identified as pre-frail $(n=74)$, and $19.6 \%(n=63)$ as frail.

In the variables for functional performance, handgrip strength frail women was reduced by about $21 \%(\mathrm{p}<0.05)$, and about $15 \%$ in frail men. The strength of the lower limbs was reduced by $25 \%$ as compared to robust individuals $(\mathrm{p}<0.05)$. In the TUG test, participants showed a mean increase of $41 \%$ in the time to complete the test as compared to robust individuals, around 3.5 seconds slower $(\mathrm{p}<0.05)$ (Table 1).

Poisson linear regression was used to assess the factors associated with frailty. In the univariate analysis, the results suggest evidence of association between age (odds ratio $=1.19$ /years, 95\%CI 1.04-1.36), TUG (OR = 1.05/s, 95\%CI 1.02-1.06). After adjusting for age and physical performance variables (handgrip strength, lower limb strength and TUG test), the TUG test remained virtually unchanged $(\mathrm{OR}=1.03 / \mathrm{s} 95 \% \mathrm{CI}$ 
Table 1 Descriptive characteristics of participants by frailty status in a city in Southern Brazil $(n=322)$.

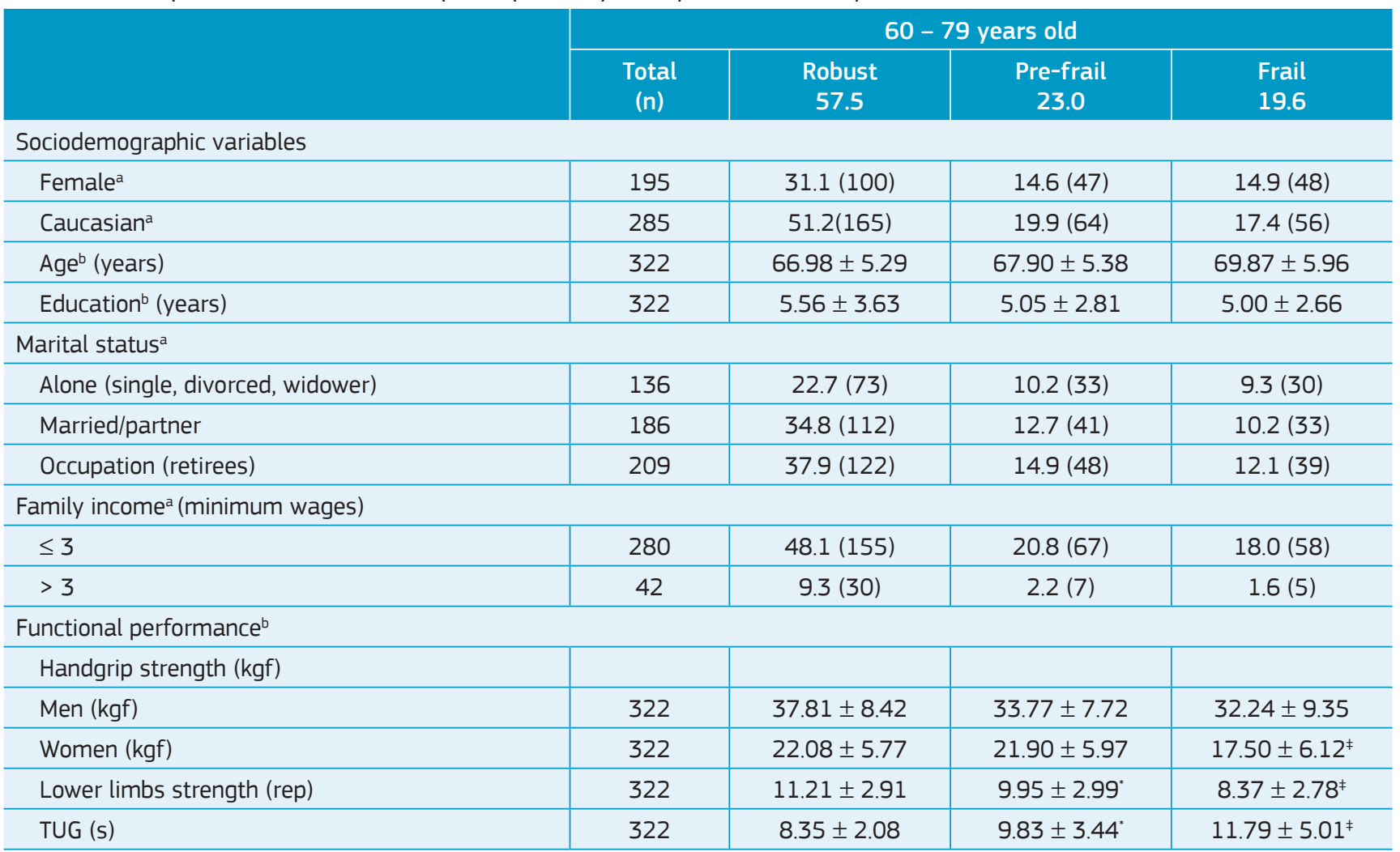

${ }^{a}$ data presented as proportion; bdata in averages and standard deviation; n: number of subjects; kgf: kilogram-force; m: meter; rep: repetitions; s: seconds; TUG: Timed Up and Go test; "ANOVA post-hoc Tukey; frail vs robust; $p<0.05$; ${ }^{\ddagger} A N O V A$ post-hoc Tukey; frail vs pre-frail and robust; $p<0.05$.

1.01-1.04). Lower limbs strength, however, appears to be an independent predictor for the classification of frailty in the final model (regression model adjusted) (Table 2).

The metric properties of TUG test in identifying frailty syndrome were studied in ROC curves (Figure 2). TUG test

Table 2. Poisson linear regression analyses in frail participants $\left(n^{-}=211\right)$.

\begin{tabular}{l|c|c}
$\begin{array}{l}\text { Predictive } \\
\text { variable frailty }\end{array}$ & OR $(95 \% \mathrm{Cl})^{\mathrm{a}}$ & OR $(95 \% \mathrm{Cl})^{\mathrm{b}}$ \\
\hline Age $(60-69$ years) & Ref. & Ref. \\
\hline $70-79$ years old & $\begin{array}{c}1.19(1.04-1.36) \\
p=0.0001\end{array}$ & $1.04(0.91-1.18)$ \\
\hline Gender (female) & $1.02(0.85-1.21)$ & \\
\hline TUG (s) & $\begin{array}{c}1.05(1.02-1.06) \\
p=0.007\end{array}$ & $\begin{array}{c}1.03(1.01-1.04) \\
p=0.0001\end{array}$ \\
\hline Handgrip & & $0.99(0.97-$ \\
strength (kgf) & & $0.100)$ \\
\hline Lower limbs & & $\begin{array}{c}0.94(0.90-0.98) \\
\text { strength (rep) }\end{array}$ \\
\hline
\end{tabular}

ref: reference; s: seconds; kgf: kilogram-force; rep: repetitions; ${ }^{a}$ model non-adjusted; bmodel adjusted for age and physical performance (handgrip strength, strength of lower limbs and TUG test).

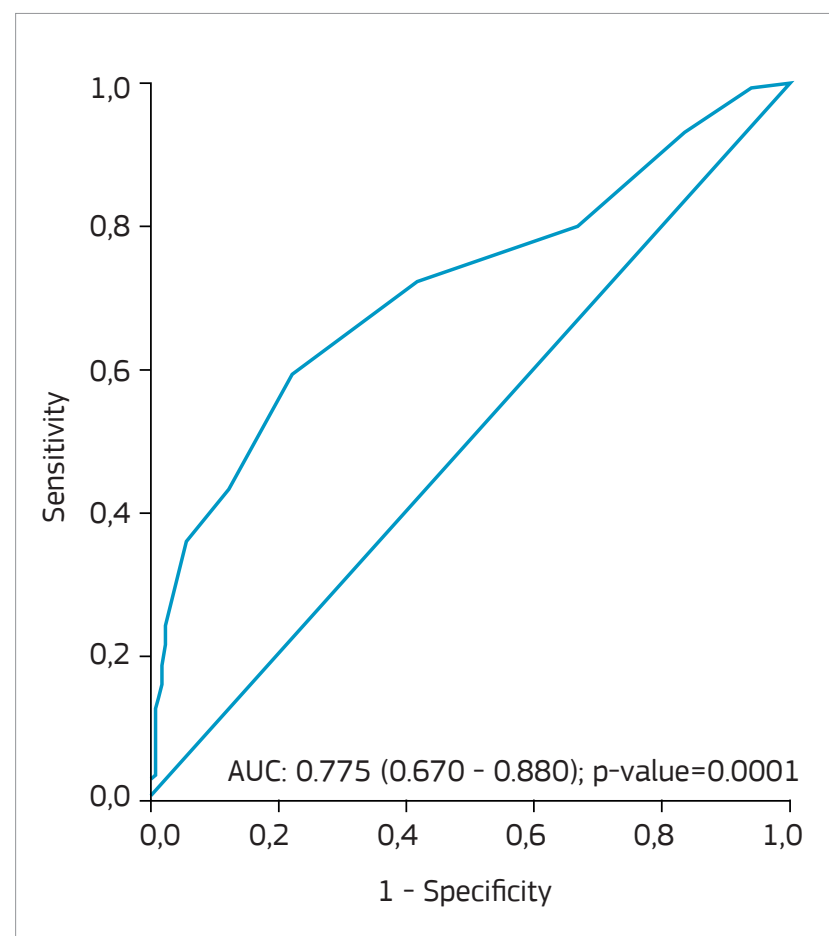

Figure 2 ROC curve demonstrating sensitivity and specificity of the cut-off point to predict frailty syndrome considering a sample of elder subjects of a city in Southern Brazil. 
demonstrated the best performance in identifying pre-frail and frail individuals (AUROC: 0.775 ; 95\%CI 0.670-0.880). A cut-off value of eight seconds for TUG test compromised best sensitivity (85.0\%), negative predictive value (78.6\%), positive likelihood ratio of 2.09 , and test accuracy of (72\%).

\section{DISCUSSION}

Several criteria to identify frail elderly subjects have been described in the literature, though few studies have devoted attention to affordable and rapid screening methods for individuals with this condition or susceptible to frail aging. A major obstacle for early detection and targeted interventions for this population is the lack of a standardized, validated method to screen for frailty syndrome. In this study, the frailty was estimated using the Fried Frailty Criteria and the TUG test on a sample of elderly community-dwelling people; the power of the TUG test alone to identify the frail population was demonstrated, and was independent of age, strength and gender.

The prevalence of pre-frailty (23.0\%) and frailty (19.6\%) found was similar to other studies in Europe, Asia, North and Central America, where data indicate that these intervals range from $2.8 \%$ to $27.3 \% .^{21,31-35}$ In Brazil, a study by Moreira and Lourenço, ${ }^{21}$ Yassuda et $a 1 .{ }^{35}$ and Alexandre et al. ${ }^{17}$ investigated the prevalence and factors associated with the frailty syndrome, and demonstrated reasonably lower prevalence between $7.0 \%$ and $10 \%$.

The TUG test showed good discriminatory power (ability to distinguish between pre-frail and frail vs. not-frail), with positive predictive value of $69.4 \%$ when the cut-off point of eight seconds for test completion was considered. The TUG test was initially developed to assess mobility and balance and predict risk of falls in the elderly. ${ }^{36}$ Recently, Wamser et al. ${ }^{37}$ evaluated the association of falls and functional performance in Brazilian healthy community-dwelling elderly. The study showed evidence of better muscle power, increased gait speed and functional exercise capacity in healthy elderly women who executed the TUG test in less time. However, the study did not show an association between number of falls and TUG. Therefore, external validation is important before applying this test in patients at large, especially since it is a physical test that depends on the subject's walking.

This change was also observed in the regression models, when it was demonstrated that the TUG completion time and the strength of lower limbs are independent predictors to the frailty (Table 2). However, when age and gender were added to the regression model, according to the formulation by Fried et al. ${ }^{6}$, these variables were not able to explain the association between the TUG completion time and the outcome. Accordingly, the results suggested that the TUG test might be useful in assessing frailty in the clinical setting.

The main advantages of this method over other instruments, including the ones proposed by Fried et al. ${ }^{6}$, Rockwood and Mitnitski, ${ }^{38}$ and the Edmonton Scale, ${ }^{39}$ are that it is fast and has low cost, therefore possible to use in the screening of frail patients in primary health care.$^{39}$ In the above-mentioned diagnostic tools, there are difficulties in its application in clinical practice. In the evaluation proposed by Fried et al. ${ }^{6}$, there are many subcomponents (depression scale, Minnesota leisure-time physical activity) that are time-consuming in the evaluation. The Edmonton Scale requires evaluator education in order to conduct the interview and score the tests. This study suggests that the completion time of the TUG test alone is responsible for identifying $70 \%$ of subjects considered as pre-frail or frail.

Greene et al. ${ }^{19}$ investigated 399 elderlies living in the community using the frailty phenotype and TUG test completion time to predict frailty. The authors suggest that the TUG test can be used as a fast and simple tool to evaluate frail subjects with $71.82 \%$ confidence (sensitivity). This data is lower to our findings, which had a sensitivity of $85.0 \%$.

This study has some potential limitations. First, our population consisted predominantly of retired elderly women, in other words, with no active lives. Second, as previously stated, the frailty criteria were not all measured exactly as proposed by Fried and colleagues, the exhaustion was measured by self-report. Third, this study has a cross-sectional design, which hinders the determination of the direction of the associations that were found. For that reason, all results should be interpreted with caution.

\section{CONCLUSION}

Current analysis suggests that the routine use of TUG as a screening tool in the elderly population is of clinical relevance because it is able to select the majority of patients at risk of fragility syndrome. Even with the limitations cited above, the data from this study shows THAт the completion time of the performance test can be a predictor with good sensitivity (85.0\%) and negative predictive value $(78.6 \%)$ even when used alone. The data suggests that the TUG test can be used as a screening tool to identify patients with probable fragility syndrome, 
being easy to apply and inexpensive. It is worth noting that the TUG test is not a single test for assessing frailty syndrome.

\section{CONFLICT OF INTEREST}

The authors report no conflict of interests.

\section{ETHICAL APPROVAL}

All procedures carried out in the present study were in accordance with

- the ethical standards of institutional and/or national research committee; and
- the 1964 Helsinki declaration and its later amendments or comparable ethical standards.

The study was approved by the Institutional Review Board of La Salle University (number of approval 642.310).

\section{INFORMED CONSENT}

Informed consent was obtained from all individuals included in the study.

\section{FUNDING}

This study was funded by a grant from Conselho Nacional de Desenvolvimento Científico e Tecnológico (CNPq), protocol number 442760/2014-0.

\section{REFERENCES}

1. Instituto Brasileiro de Geografia e Estatística. Planejamento. Brasil; 2014.

2. Bandeen-Roche K, Xue QL, Ferrucci L, Walston J, Guralnik JM, Chaves $P$, et al. Phenotype of frailty: characterization in the women's health and aging studies. J Gerontol A Biol Sci Med Sci. 2006;61(3):262-6.

3. Morley JE, Vellas B, van Kan GA, Anker SD, Bauer JM, Bernabei $\mathrm{R}$, et al. Frailty consensus: a call to action. J Am Med Dir Assoc. 2013;14(6):392-7.

4. Garcia-Garcia FJ, Gutierrez Avila G, Alfaro-Acha A, Amor Andres MS, De Los Angeles De La Torre Lanza M, Escribano Aparicio MV, et al. The prevalence of frailty syndrome in an older population from Spain. The Toledo Study for Healthy Aging. J Nutr Health Aging. 2011;15(10):852-6.

5. Frisoli A, Ingham SJ, Paes Â, Tinoco E, Greco A, Zanata N, et al. Frailty predictors and outcomes among older patients with cardiovascular disease: Data from Fragicor. Arch Gerontol Geriatr. 2015;61(1):1-7.

6. Fried LP, Tangen CM, Walston J, Newman AB, Hirsch C, Gottdiener J, et al. Frailty in older adults: evidence for a phenotype. $J$ Gerontol A Biol Sci Med Sci. 2001;56(3):M146-56.

7. Kulmala J, Nykänen I, Hartikainen S. Frailty as a predictor of all-cause mortality in older men and women. Geriatr Gerontol Int. 2014;14(4):899-905.

8. Song X, Mitnitski A, Rockwood K. Prevalence and 10-year outcomes of frailty in older adults in relation to deficit accumulation. J Am Geriatr Soc. 2010;58(4):681-7.

9. Woods NF, LaCroix AZ, Gray SL, Aragaki A, Cochrane BB, Brunner RL, et al. Frailty: emergence and consequences in women aged 65 and older in the Women's Health Initiative Observational Study. J Am Geriatr Soc. 2005;53(8):1321-30.

10. Szanton SL, Seplaki CL, Thorpe RJ, Jr., Allen JK, Fried LP. Socioeconomic status is associated with frailty: the Women's Health and Aging Studies. J Epidemiol Community Health. 2010;64(1):63-7.

11. Reiner AP, Aragaki AK, Gray SL, Wactawski-Wende J, Cauley JA, Cochrane $\mathrm{BB}$, et al. Inflammation and thrombosis biomarkers and incident frailty in postmenopausal women. Am J Med. 2009;122(10):947-54.

12. Barzilay JI, Blaum C, Moore T, Xue QL, Hirsch CH, Walston JD, et al. Insulin resistance and inflammation as precursors of frailty: the Cardiovascular Health Study. Arch Intern Med. 2007;167(7):635-41.

13. Shamliyan T, Talley KM, Ramakrishnan R, Kane RL. Association of frailty with survival: a systematic literature review. Ageing Res Rev. 2013;12(2):719-36.

14. McNallan SM, Singh M, Chamberlain AM, Kane RL, Dunlay SM, Redfield $\mathrm{MM}$, et al. Frailty and healthcare utilization among patients with heart failure in the community. JACC Heart Fail. 2013;1(2):135-41.
15. Pugh JA, Wang CP, Espinoza SE, Noel PH, Bollinger M, Amuan M, et al. Influence of frailty-related diagnoses, high-risk prescribing in elderly adults, and primary care use on readmissions in fewer than 30 days for veterans aged 65 and older. J Am Geriatr Soc. 2014;62(2):291-8.

16. Bagshaw SM, Stelfox HT, McDermid RC, Rolfson DB, Tsuyuki RT, Baig N, et al. Association between frailty and short- and long-term outcomes among critically ill patients: a multicentre prospective cohort study. CMAJ. 2014;186(2):E95-102.

17. Alexandre TaS, Corona LP, Nunes DP, Santos JL, Duarte YA, Lebrão ML. Similarities among factors associated with components of frailty in elderly: SABE Study. J Aging Health. 2014;26(3):441-57.

18. Lee L, Patel T, Hillier LM, Maulkhan N, Slonim K, Costa A. Identifying frailty in primary care: A systematic review. Geriatr Gerontol Int. 2017.

19. Greene BR, Doheny EP, O'Halloran A, Anne Kenny R. Frailty status can be accurately assessed using inertial sensors and the TUG test. Age Ageing. 2014;43(3):406-11.

20. Savva GM, Donoghue OA, Horgan F, O'Regan C, Cronin H, Kenny RA. Using timed up-and-go to identify frail members of the older population. J Gerontol A Biol Sci Med Sci. 2013;68(4):441-6.

21. Moreira VG, Lourenço RA. Prevalence and factors associated with frailty in an older population from the city of Rio de Janeiro, Brazil: the FIBRA-RJ Study. Clinics (São Paulo). 2013;68(7):979-85.

22. Alexandre TS, de Oliveira Duarte YA, Ferreira Santos JL, Wong R, Lebrão ML. Prevalence and Associated Factors of Sarcopenia among Elderly in Brazil: Findings from the SABE Study. J Nutr Health Aging. 2014;18(3):284-90.

23. Rikli RE, Jones CJ. Development and validation of criterion-referenced clinically relevant fitness standards for maintaining physical independence in later years. Gerontologist. 2013;53(2):255-67.

24. Jones CJ, Rikli RE, Beam WC. A 30-s chair-stand test as a measure of lower body strength in community-residing older adults. Res Q Exerc Sport. 1999;70(2):113-9.

25. Op het Veld LP, van Rossum E, Kempen GI, de Vet HC, Hajema K, Beurskens AJ. Fried phenotype of frailty: cross-sectional comparison of three frailty stages on various health domains. BMC Geriatr. 2015;15:77.

26. Nunes DP, Duarte YA, Santos JL, Lebrão ML. Screening for frailty in older adults using a self-reported instrument. Rev Saúde Pública. 2015;49:2.

27. Benedetti MG, Barros MV. Aplicação do Questionário Internacional de Atividade Física para avaliação do nível de atividades físicas de mulheres idosas: validade concorrente e reprodutibilidade teste/ reteste. Rev Bras Ciênc Mov. 2004;12(1):25-33. 
28. Benedetti AP, Rodriguez-Añez CR, Mazo GZ, Petroski EL. Reprodutibilidade e validade do Questionário Internacional de Atividade Física (IPAQ) em homens idosos. Rev Bras Med Esporte. 2007;13(1):11-6.

29. Guralnik JM, Simonsick EM, Ferrucci L, Glynn RJ, Berkman LF, Blazer $D G$, et al. A short physical performance battery assessing lower extremity function: association with self-reported disability and prediction of mortality and nursing home admission. J Gerontol. 1994; 49(2):M85-94.

30. Fried LP, Tangen CM, Walston J, Newman AB, Hirsch C, Gottdiener J, et al. Frailty in older adults: evidence for a phenotype. J Gerontol A Biol Sci Med Sci. 2001;56(3):M146-56.

31. Manrique-Espinoza B, Salinas-Rodríguez A, Salgado de Snyder N, Moreno-Tamayo K, Gutiérrez-Robledo LM, Avila-Funes JA. Frailty and Social Vulnerability in Mexican Deprived and Rural Settings. J Aging Health. 2016;28(4):740-52.

32. Masel MC, Howrey B, Peek MK. The effect of acculturation on frailty among older Mexican Americans. J Aging Health. 2011;23(4):704-13.

33. Santos-Eggimann B, Cuénoud P, Spagnoli J, Junod J. Prevalence of frailty in middle-aged and older community-dwelling Europeans living in 10 countries. J Gerontol A Biol Sci Med Sci. 2009;64(6): 675-81.
34. Wong CH, Weiss D, Sourial N, Karunananthan S, Quail JM, Wolfson C, et al. Frailty and its association with disability and comorbidity in a community-dwelling sample of seniors in Montreal: a cross-sectional study. Aging Clin Exp Res. 2010;22(1):54-62.

35. Yassuda MS, Lopes A, Cachioni M, Falcão DV, Batistoni SS, Guimaraes VV, et al. Frailty criteria and cognitive performance are related: data from the FIBRA study in Ermelino Matarazzo, São Paulo, Brazil. J Nutr Health Aging. 2012;16(1):55-61.

36. Thrane G, Joakimsen RM, Thornquist E. The association between timed up and go test and history of falls: the Tromsø study. BMC Geriatr. 2007;7:1.

37. Wamser VS, Paula JA, Schieferdecker MEM, Amarante TP, Pinottie $F$, Coelho RA, et al. Best performance in the Timed Up and Go is associated to best functional performance in community-dwelling older women. Geriatr Gerontol Aging. 2015;9(4):138-43.

38. Rockwood K, Mitnitski A. Frailty in relation to the accumulation of deficits. J Gerontol A Biol Sci Med Sci. 2007;62(7):722-7.

39. Fabrício-Wehbe SC, Cruz IR, Haas VJ, Diniz MA, Dantas RA, Rodrigues RA. Reproducibility of the Brazilian version of the Edmonton Frail Scale for elderly living in the community. Rev Lat Am Enferm. 2013:21(6):1330-6. 